\title{
POTENTIALS OF MORINGA (Moringa oleifera) SEED OIL IN ENHANCING THE NUTRITIONAL QUALITY AND STABILITY OF SOYBEAN OIL
}

${ }^{* 1}$ Iranloye, Y.M, ${ }^{2}$ Fapojuwo, O.O., ${ }^{3}$ Abioye V.F. and ${ }^{1}$ Olaniran A. F.

1Department of Food Science and Nutrition, Landmark University Omu-Aran, Kwara State, Nigeria.

2Department of Food Science and Technology, Kwara State University, Malete, Kwara State Nigeria.

${ }^{3}$ Department of Food Science and Engineering, Ladoke Akintola University of Technology, Ogbomosho Oyo State, Nigeria

Corresponding Author: iranloye.yetunde@Imu.edu.ng; yetybaby@gmail.com

\section{ABSTRACT}

Partial hydrogenation method has been used to improve the stability of soybean oil, though it results in the production of trans-fatty acid. The objective of this study was to establish the potential of moringa oil to improve the stability and nutritional quality of soybean oil. Oil samples were extracted from sundried soybean and Moringa seeds using Soxhlet extraction techniques. Soybean powder was mixed with Moringa powder at ratio 50:50 and 70:30, and the oil was extracted afterward. The fatty acid profile of the extracted oil from these blends was studied using Gas Chromatography-Mass Spectrophotometry (GC-MS) technique. The results showed that commercial soybean oil and the blended soybean/moringa oil of ratio 50:50 and 70:30 had a polyunsaturated fatty acid of $52.70 \%, 22.18 \%$ and $35.73 \%$ respectively; monounsaturated fatty acid $27.22 \%$, $46.61 \%$ and $58.79 \%$ respectively; saturated fatty acid $19.01 \%, 19.02 \%$ and $17.86 \%$ respectively. Also, trans-fatty acid (0.003-0.395\%) was obtained in the commercial soybean oil sample. The blended soybean/moringa oil offers a better option than the use of partially hydrogenation in commercial soybean oil.

Keywords: Moringa seed oil, soybean oil, partial hydrogenation, trans-fatty acid, Oil blending. 


\section{INTRODUCTION}

Soybean oil is a well-accepted vegetable oil. Its usage is known with reduced risk of cancer of the breast and prostate (Zhang et al., 2011). Nevertheless, it has less oxidative stability when stored at room temperature as well as when they are used in the kitchen for frying and cooking at high temperature (Kozlowska and Gruczynska 2018). Various methods have been developed to improve the oxidative stability of soybean oil. These include partial hydrogenation, fatty acid modification (inter-esterification), genetic engineering and blending with more saturated and monounsaturated oils to lessen the quantity of polyunsaturated fatty acids (Cuesta et al., 1993; Su and White, 2004, Adel et al., 2015, Berry et al., 2019). Partial hydrogenation improves the stability of edible oils but produces trans-fats which have been associated with risks of heart disease in humans (Downs et al., 2013). The inter-esterification process to modify polyunsaturated fatty acids of oils with other stable vegetable oils increases processing costs which is not economically acceptable (Menaa et al., 2013). Like any new technology, genetic engineering carries with it some level of uncertainty and requires ways to predict and assess potential unintended effects.

Moringa seed oil is rich in oleic acid (>70\%) and it is one of the major sources of naturally antioxidants (Ojiako and Okeke, 2013). Moringa oleifera oil may serve as an additional source of edible oil for domestic and industrial uses (Conrad et al., 2020). It is a potential vegetable oil that can be blended with soybean oil to enhance its oxidative stability as well as its nutritional and deep-frying qualities. There is a pressing need for widely usable and easily available bioactive lipids and natural antioxidants (Gupta and Singh, 2013).

Soybean oil in its natural form has an appreciable level of omega-3- fatty acids which add to the nutritive value of the oil. However, it is known that partial hydrogenation may destroy some of the omega-3-fatty acid and produces transfatty acid in the oil. Instead of partial hydrogenation of soybean oil to improve stability, the numerous antioxidants present may be lost. The enhancement of soybean oil by mixing with other vegetable oils such as palm oleic, sunflower, mustard seed has been reported (Abdulkarim and Myat, 2010). Haridas et al (2015), blended rice bran oil and safflower oil to produce anti-lipidermic effect on the oil. The use of temnocalyx obovatus extracts as an alternative natural antioxidant to improve sunflower and soyabean oil oxidative stability was reported by Dzomba et al., 2012. Adamsu, 2015 reported a positive effect of co-pressing on niger seed oil with black cumin seed oil on yield and oxidative stability and sensory properties of cold pressed oil. Ebrahimzadeh et al (2015) mixed soybean oil with 
urtica dioica to enhance the stability of soybean oil. To overcome the problem of poor stability of soybean oil, blending of vegetable oil that is high in oleic acid can improve the oxidative stability, physicochemical properties of vegetable oils besides enhancement of nutritional quality. The present study was therefore designed to determine the effect of moringa seed oil blend on the oxidative stability and nutritional quality of soybean oil.

\section{MATERIALS AND METHODS}

\section{Materials}

Soybean and Moringa seeds were obtained locally from an open market at Yoruba Road, Ilorin, Kwara State while the commercial soybean oil was purchased from Shoprite, Kwara State, Nigeria. All the materials were stored at room temperature until further analyses. All the analytical reagents used were of analytical grade.

\section{Methods}

\section{Extraction of Oils}

About $1,500 \mathrm{~g}$ of soybean seeds were sorted, dried and milled into powder. About $800 \mathrm{~g}$ of Moringa seed was sorted, dried and milled into powder. Oil was extracted as designed by Evwierhoma and Ekop (2016), using Soxhlet extraction technique with n-hexane as solvent. Three different blends of 100:0; 70:30; 50:50, respectively, for soybean and moringa oil were prepared.

\section{Determination of Fatty Acid Composition}

The preparation of fatty acid methyl esters (FAMEs) was done as described by $\mathrm{Li}$ et al (2012) and the FAME was removed and dried with anhydrous $\mathrm{Na}_{2} \mathrm{SO}_{4}$, then diluted to a concentration of $5-10 \%$ for injection into the gas chromatography, the FAMEs was removed and dried with anhydrous $\mathrm{Na}_{2} \mathrm{SO}_{4}$, it was then diluted to a concentration of $5-10 \%$ for injection into the Gas chromatography-mass spectrometry, (GC/MS) analysis was carried out with an Agilent 6890-5973 (Agilent Technologies, CA, USA) instrument. Separating procedure was achieved on an Agilent HP-88 capillary column $(100 \times 0.25 \mathrm{~mm}$ i.d., film thickness $0.2 \mu \mathrm{m})$. The conditions of operation were as follows: carrier gas pressure, $100 \mathrm{kPa}$; carrier gas, helium; split ratio was 1:30; injection temperature, $250^{\circ} \mathrm{C}$; scanning scope: $50-550 \mathrm{amu}$; ionization voltage: $70 \mathrm{eV}$. Oven temperature was programmed as follows: it was held at $80^{\circ} \mathrm{C}$ for $5 \mathrm{~min}$, and then rising to $150^{\circ} \mathrm{C}$ at $10^{\circ} \mathrm{C} / \mathrm{min}$, and held for 2 min at $150^{\circ} \mathrm{C}$; then continuously rising to $230^{\circ} \mathrm{C}$ at $5^{\circ} \mathrm{C} / \mathrm{min}$ and held for $10 \mathrm{~min}$. The specific fatty acids were 
identified and quantified by comparing their retention times with external standards. Fatty acid composition of the oil was reported as total percentage of total fatty acids.

\section{RESULTS AND DISCUSSION}

The composition of the fatty acid of oil samples is as shown in Table 1. Transfatty acid was present in the commercial soybean oil while the freshly extracted and the blended oils did not indicate the presence of trans-fatty acids. This result is in line with previous researches which reported that though partial hydrogenation improves stability of edible oil, it results in the production of transfats (Da Silva et al., 2010, Downs et al., 2013). This implies that commercial soybean oils that are relatively stable on the shelf might have undergone partial hydrogenation. The fatty acids composition of the extracted soybean oil is as shown in Table 1. It has $54.59 \%$ Linoleic acid and $7.30 \%$ Linolenic acid while $48.43 \%$ and $4.40 \%$ were obtained for the commercial soybean oil for Linoleic acid and Linolenic acid respectively. The reduction of linoleic and linolenic acid of commercial soybean oil, could be due to the loss of unsaturation as a result of partial hydrogenation. The result obtained is within the range reported for fatty acid composition of soybean oil in several works (Reena and Lokesh 2007). The blending of moringa oil with soybean oil had positive effects on the composition of the fatty acids. The relative percentage composition of the level of saturation of the oil samples are as shown in Table 2. Commercial soybean oil and soybean/moringa oil blend (50:50) had slightly higher percentage of saturated fatty acids, $19.01 \%$ and $19.02 \%$ respectively, compared to extracted soybean oil and soybean/moringa oil blend (70:30) which had $16.43 \%$ and $17.86 \%$ respectively.

The soybean/moringa oil blends (50:50 and 70:30) had higher monounsaturated fatty acid $(58.79 \%$ and $46.41 \%)$ and lowest amount of polyunsaturated fatty acid $(22.18 \%$ and $35.73 \%)$, respectively. This is possibly due to the effect of moringa oil composition that has high content of oleic acid. The extracted soybean oil had the highest percentage of polyunsaturated fatty acid (61.8\%) and the lowest percentage of monounsaturated fatty acid $(21.67 \%)$. Blending of soybean oil with Moringa oleifera oil did not significantly modify the saturation level of the oil samples but there was a significant modification on the fatty acids composition. Soybean oil in its natural form has an appreciable amount of polyunsaturated acid and low percentage of monounsaturated fatty acids; however, it has less oxidative stability. Blending of soybean oil with other oils has been reported to enhance its oxidative stability and modify the fatty acid profile (Abdulkarim and 
Myat, 2010 and Naghshineh et al., 2010). Thus, the result obtained from this study shows that soybean/moringa oil blends has the lowest percentage of polyunsaturated fatty acids and the highest amount of monounsaturated fatty acids. This confirms the reports from previous research that blending soybean oils with other oils may yield positive effects on the stability and fatty acid profile of the oil (Yang Li et al., 2014). This may probably be a nutritional advantage for the blended oil as oleic acid has been shown to have beneficial health effects. Oleic acid has been associated with decreased low-density lipoprotein (LDL) cholesterol, and possibly increased high-density lipoprotein cholesterol (Nadeem and Imran 2016). Dinicolantonio and O'Keefe (2018) also reported that oleic acid may be responsible for the hypotensive (blood pressure reducing) effects of olive oil.

The extracted soybean oil had the highest amount of omega-3 fatty acid (7.3\%). This was probably because the oil did not go through partial hydrogenation. Thus, the omega-3 fatty-acid were preserved. However, the commercial soybean oil had a low content of omega-3 fatty acid (4.4\%). This was probably because it was partially hydrogenated. Omega-3 fatty acid has been reported to have possible impact in prevention of coronary heart disease, cardiovascular diseases and related disease (Torpy et al., 2006, Bowen et al., 2016). Nutritionally, omega3 fatty acid determines the quality of the oil indicating that the higher the percentage of omega-3 fatty acid in the oil samples the better the nutritional quality. The oil blended with $70: 30$, soybean and moringa oil had $4.61 \%$ of omega-3 fatty acid while the oil blends (50:50) had the lowest amount of omega3 fatty acid (2.8\%). Higher contents of omega-3 fatty acid were obtained with 70:30 oil blends than the commercial oil samples that had gone through partial hydrogenation.

Extracted soybean oil had the highest amount of omega- 6 fatty acid (54.59\%). Omega- 6 fatty acid has been reported to help in the maintenance of healthy bone, regulating metabolism, and in stimulating skin and hair growth (Al-khudairy et al., 2015), which indicates a better nutritional quality. The oil blends (50:50) and (70:30) had the highest percentage of omega- 9 fatty acid (57.76\%) and (45.54\%). It has also been reported that omega-9 fatty acids regulate pro-and antiinflammatory processes via its ability to stimulate enzymes and produce cytokines and other acute phase molecules (Maskrey et al., 2011). This is an indication that the blending increased the omega-9 content in the oil and hence a better quality. 
Table 1: Fatty acid composition (\%) of vegetable oil samples

\begin{tabular}{cccccc}
\hline $\begin{array}{c}\text { Fatty } \\
\text { acid }\end{array}$ & $\begin{array}{c}\text { Extracted } \\
\text { Moringa } \\
\text { Oil }\end{array}$ & $\begin{array}{c}\text { Extracted } \\
\text { soybean } \\
\text { oil }\end{array}$ & $\begin{array}{c}\text { Commercial } \\
\text { soybean oil }\end{array}$ & $\begin{array}{c}\text { Soybean/moringa } \\
\text { oil blend (50:50) }\end{array}$ & $\begin{array}{c}\text { Soybean/moringa } \\
\text { oil blend (70:30) }\end{array}$ \\
\hline C12:0 & ND & ND & 2.49 & ND & ND \\
C14:0 & ND & ND & 0.93 & ND & 0.15 \\
C16:0 & 7.72 & ND & 12.32 & 8.79 & 11.2 \\
C16:1 & 0.93 & ND & ND & ND & ND \\
C16:1t & ND & ND & 0.003 & ND & ND \\
C18:0 & 3.52 & 4.13 & 4.2 & 4.31 & 4.2 \\
C18:1 & 76.52 & ND & ND & ND & ND \\
C18:1n9t & ND & ND & 0.395 & ND & ND \\
C18:1n9c & ND & 21.67 & 27.22 & 57.76 & 45.54 \\
C18:2n6c & ND & 54.59 & 48.43 & 19.38 & 31.12 \\
C18:3n3 & ND & 7.3 & 4.4 & 2.8 & 4.61 \\
C20:0 & 2.49 & ND & ND & 1.79 & 0.50 \\
C21:0 & ND & ND & ND & 2.88 & ND \\
C22.0 & 0.5 & ND & ND & 1.25 & ND \\
C22:1 & 2.48 & ND & ND & ND & ND \\
C23:0 & 2.62 & ND & ND & ND & ND \\
\hline
\end{tabular}

ND (Not Detected)

Table 2: Classes of fatty acid in their relative percentage

\begin{tabular}{lrrrrrrr}
\hline Samples & SFA & MUFA & PUFA & n-3 & n-6 & n-6/n-3 & t-fats \\
\hline ESO & 16.43 & 21.67 & 61.89 & 7.30 & 54.59 & 7.48 & ND \\
CSO & 19.01 & 27.22 & 52.70 & 4.40 & 48.30 & 10.97 & 0.4 \\
SMO (50:50) & 19.02 & 58.79 & 22.18 & 2.80 & 19.38 & 6.92 & ND \\
SMO (70:30) & 17.86 & 46.41 & 35.73 & 4.61 & 31.12 & 6.75 & ND \\
\hline
\end{tabular}

ND (Not Detected)

SFA- Saturated fatty acid

MUFA- Monounsaturated fatty acid

PUFA- Polyunsaturated fatty acid

n-3- omega-3 fatty Acid

n-6- omega-6 fatty Acid

t-Fats-Trans-fatty Acid

ESO- Extracted soybean oil

CSO- Commercial Soybean oil

SMO (50:50) - Soybean/Moringa oil blend (50:50)

SMO (70:30) - Soybean/Moringa oil blend (70:30) 


\section{CONCLUSION}

Commercial soybean oil contains trans-fatty acid due to the use of partial hydrogenation to improve its stability. In this research, extracted soybean oil was mixed with moringa oil at different ratios (50:50 and 70:30). The result showed that the mixed soybean/moringa oil did not contain trans-fatty acid. The polyunsaturated fatty acid of the mixed soybean/moringa oil was reduced as compared to the commercially used soybean oil. Also, the Omega-3 value of Soybean/moringa oil of ratio $70: 30(4.61 \%)$ was higher than 50:50 (2.8\%) and commercial soybean oil (4.4\%). It can be concluded that the blended soybean/moringa oil offers a better option than the use of partially hydrogenated commercial soybean oil. Also, the blending of Moringa oil with soybean can be recommended since they contain high percentage of mono-unsaturated fatty acid.

\section{REFERENCES}

Abdulkarim, S.M and Myat, M.W. (2010). Sensory and physicochemical qualities of palm olein and sesame seed oil blends during frying of banana chips. Journal of Agricultural Science, 2, 18-29.

Adamsu, F. (2015). Effect of co-pressing of niger (Guizotia abyssinicaCass.) and black cumin (Nigella sativa) seeds on yield, oxidative stability and sensory properties of cold pressed oil. Ethiopian Journal of Science and Technology, 8(2), 61- 70.

Adel, Y.G., Shaker, M.A., and Mounir, M.E. (2015). Improving quality of the Egyptian subsidized oil. International Food Research Journal, 22(5), 19111917

Al-khudairy, L., Hartley, L., Clar, C., Flowers, N., Hooper, L., Rees K. (2015). Omega 6 fatty acids for the Primary Prevention of Cardiovascular Disease. Cohrane Database of Systematic Reviews. Issue 11 Art NO: CD011094

Berry, S.E., Bruce, J.H., Steenson, S., Stanner, S., Buttriss, J.L., Spiro A, Gibson, P.S., Bowler, I., Dionisi, F., Farrell, L., Glass, A., Lovegrove, J.A, Nicholas, J., Peacock, E., Porter, S., Mensink, R.P., and Hall W.L. (2019). Interesterified fats: What are they and why are they used? A briefing report from the Round table on Interesterified Fats in Foods. Nutrition Bulletin, 44, 363-380. 
Bowen, K.J., Williams, S.H., Penny, M.K. (2016). Omega-3 Fatty Acids and Cardiovascular Disease: Are There Benefits? Current Treatment Options in Cardiovascular Medicine, 18(11), 69.

Conrad, O., Enameguono, O., Ayodeji, A., and Evans, E. (2020). Review Utilization of Moringa oleifera oil for biodiesel production: A systematic review. AIMS Energy, 8(1): 102-121.

Cuesta, C., Sanchez-Muniz, F.J., Garrido-Polonio, C., Lopez-Varela, S. and Arroyo, R. (1993). Thermo-oxidative and hydrolytic changes in sunflower oil used in frying with a fast turnover of fresh oil. Journal of the American Oil Chemists Society, 70, 1069-1073.

Dzomba, P., Togarepi, E., Musekiwa, C., and Chagwiza, C.J. (2012). Improving the oxidative stability of soya and sunflower oil using Temnocalyx obovatus extracts. African Journal of Biotechnology, 11(50), 11099-11103.

Da Silva, R.C., Soares, D.F., Lourenco, M.B., Soares, F., Da Silva, K.G., and Goncalves M.A., (2010). Structured lipids obtained by chemical interesterification of olive oil and palm stearin. LWT-Food Science and Technology, 43(5),752-758.

Dinicolantonio, J.J, and O'Keefe J.H. (2018). Effects of dietary fats on blood lipids: a review of direct comparison trials. Open heart, 5(2), e000871

Downs, S.M., Gupta, V., Ghosh-Jerath, S., Lock, K., Thow, A.M., and Singh A. (2013). Reformulating partially hydrogenated vegetable oils to maximise health gains in India: is it feasible and will it meet consumer demand. BioMed Central Public Health,13(1139), 1-9.

Ebrahimzadeh, M.A., Gharekhani M., Ghorbani M., Dargany, P. (2015). Effects of Extracts of Aerial Parts of Urtica dioca (Urticaceae) on the stability of Soybean oil. Tropical Journal of Pharmaceutical Research, 14(1),125-131.

Evwierhoma, E.T. and Ekop, I. E. (2016). Extraction and Characterization of Oils from Local Seeds. International Journal of Scientific \& Engineering Research, 7(5), 1280-1294

Gupta, R.K. and Singh, N. (2013). Morinda citrifolia (Noni) alters oxidative stress marker and antioxidant activity in cervical cancer cell lines. Asian pacific Journal of Cancer Prevention, 14, 4603-4606. 
Haridas, U., Devaraju, C.J. and Shashank, R.J. (2015). Anti-inflammatory properties of blended edible oil with synergistic antioxidants. Indian Journal of Endocrinology Metabolism, 19(4), 511-519.

Reena M.B. and Lokesh B.R. (2007). Hypolipidermic effect of oils with balanced amounts of fatty acids obtained by blending and interesterification of coconut oil with rice bran oil or sesame oil. Journal of Agricultural and Food Chemistry, 55(25), 10461-10469

Kozlowska, M. and Gruczynska E. (2018). Comparison of the oxidative stability of soybean and sunflower oils enriched with herbal plant extracts. Chemical Papers, 72, 2607-2615.

Li, Y., Zhang, Y., Wang, M. (2012). Simplex-centriod mixture design applied to aqeous enzymatic extraction of fatty acid balanced oil from mixed seeds. Journal of American oil Chemical Society, 90(3), 349-357.

Menaa, F., Menaa, A., Tréton, J. and Menaa, B. (2013). Technological Approaches to Minimize Industrial Trans Fatty Acids in Foods. Journal of Food Science, 78(3), 377-386.

Maskrey, B.H., Megson, I.L., Whitfield, PD., Rossi, A.G. (2011). Mechanisms of resolution of inflammation: a focus on cardiovascular disease. Arteriosclerosis, Thrombosis and Vascular Biology, 31(5), 1001-1006.

Nadeem, M. and Imran, M. (2016). Promising features of Moringa oleifera oil: Recent updates and perspectives. Lipids in Health and Disease, 15, 212220.

Naghshineh, M., Ariffin, A.A and Ghazali H.M (2010). Effect of saturated/unsaturated fatty acid ratio on physicochemical properties of palmaolein-olive blend. Journal of American Oil Chemists Society, 87(3), 225-262

Ojiako, E.N. and Okeke, C.C. (2013). Determination of antioxidant of Moringa oleifera seed oil and its use in the production of a body cream. Asian Journal of Plant Science and Research, 3(3), 1-4.

Su, C. and White P. (2004). Frying stability of high-oleate and regular soybean oil blends. Journal of American Oil Chemists Society, 81, 783-788. 
Torpy, J.M., Lynm, C. and Glass, R.M (2006). Eating fish: Health benefits and risks. The Journal of the American Medical Association, 296(15), 1926.

Yang Li, Wen-Jun Ma, Bao-Kun Qi, Sami Rokayya, Dan Li, Jing Wang, Hong-Xia Feng, Xiao-Nan Sui, and Lian-Zhou Jiang. (2014) Blending of Soybean Oil with Selected Vegetable Oils: Impact on Oxidative Stability and Radical Scavenging Activity. Asian Pacific Journal of Cancer Prevention. 15(6), 2583-2589.

Zhang, Y.F., Zhou, L., Jiao, S.C., Xu, L.Z. (2011). Relationship between soy food intake and breast cancer in China. Asian Pacific Journal of Cancer Prevention, 12(11), 2837-2840. 